\title{
Identifying areas of low-profile ice sheet and outcrop dam- ming in the Antarctic ice sheet by ERS-1 satellite altimetry
}

\author{
David G. Vaughan, ${ }^{1}$ Jonathan L. Bamber ${ }^{2}$ \\ ${ }^{1}$ British Antarctic Survey, Natural Environment Research Council, High Cross, Madingley Road, Cambridge CB3 OET, England \\ ${ }^{2}$ Centre for Remote Sensing, Department of Geography, University of Bristol, Bristol BS8 1SS, England
}

\begin{abstract}
A digital elevation model (DEM) of the surface of the Antarctic ice sheet is compared with a simple two-dimensional ice-flow model to illuminate gross distortions ( $>500 \mathrm{~m}$ ) of the ice-surface elevation. We use a DEM derived from ERS-1 satellite altimetry, airborne data and TWERLE balloon data. This is compared with an ice-sheet elevation model generated by applying theoretical surface elevations, calculated for twodimensional ice flow, to isolines of distance from the grounding line (continentality). The model is scaled using only one parameter, to match the measured surface elevation at Dome Argus. The model is far from rigorous, violating continuity conditions, ignoring variations in surface mass balance and temperature, and assuming uniform basal conditions. However, the comparison of model and observed surface elevations is illuminating in terms of the behaviour of the ice sheet at a continental scale. Across the ice sheet the rms difference between modelled elevation and the DEM is around $300 \mathrm{~m}$, but much of this results from isolated areas of much greater disagreement. We ascribe these gross differences to the effects of basal conditions. In four areas, the observed surface is more than $500 \mathrm{~m}$ higher than the modelled surface. Most of these are immediately upstream of substantial areas of rock outcrop and are caused by the damming effect of these mountain ranges. In nine areas, the measured surface is more than $500 \mathrm{~m}$ lower than predicted. Eight of these areas, in West Antarctica and the Lambert Glacier basin, are associated with suspected areas of basal sliding. The ninth is an area of $250000 \mathrm{~km}^{2}$ in East Antarctica not previously noted as having unusual flow characteristics, but for which very few data exist. We speculate that this area results from unusual basal conditions resulting in a low-profile ice sheet. A low-profile ice sheet of this size within the East Antarctic ice sheet indicates that basal conditions are perhaps more variable than previously thought.
\end{abstract}

\section{INTRODUCTION}

Over the last two decades considerable effort has been expended to develop convincing ice-sheet models. These range from two-dimensional, steady-state snapshot models (e.g. Whillans and Johnsen, 1983; Waddington and Clarke, 1988; Jóhannesson and others, 1989) to three-dimensional time-evolving thermomechanical models (e.g. Budd and Jenssen, 1989; Huybrechts, 1993; Fabre and others, 1995; Greve and Hutter, 1995). Together, these models form a hierarchy of tools tuned to answer particular glaciological questions. While the trend is towards more complex models that include more mechanisms and interactions, it is arguably true that we have not yet fully exploited the simple models for the insight that they can provide into the behaviour of the ice sheet.

In this study we use a model that is simple in concept and application to predict the surface elevation of the ice sheet. While this model ignores many of the physical processes that would be required to reproduce the details of the ice flow, most notably basal topography and drag conditions, it can usefully be considered as a zero-order model of the ice sheet. We then compare the predicted surface elevation with the best available continental DEM to highlight the grossest model/observation differences. Finally, we attempt to ascribe these gross distortions of the ice-sheet surface to known areas of basal sliding and rock outcrop.

\section{ANTARCTIC DIGITAL ELEVATION MODEL: OBSERVED DEM}

This study arose from an attempt to assess a new digital elevation model (DEM) of Antarctica (Fig. 1) previously presented and discussed by Bamber (1994) and Bamber and Huybrechts (1996). For most of the continent, the DEM was derived from over 20000000 measurements of surface elevation retrieved from eight 35 day repeat cycles of the ERS-1 satellite radar altimeter. The spacing of satellite tracks and considerable footprint of the altimeter beam mean that short wavelength features are lost from the satellite altimetry, and the derived DEM is smoothed. Bamber (1994) estimated the random error in the altimeter measurements to be $\pm 2.4 \mathrm{~m}$, with similar magnitude for the biases. In areas of higher surface slope, accuracy is further reduced. Around the coast and in mountainous areas where the altimeter failed to maintain track on the ice-sheet surface, the altimeter measurements were supplemented with data taken from the Antarctic Digital Database (SCAR, 1993).

Beyond the orbital limit of ERS-1, south of $81.5^{\circ} \mathrm{S}$, data from the Scott Polar Research Institute Folio Series (Drewry, 1983) and data from the original airborne radar 


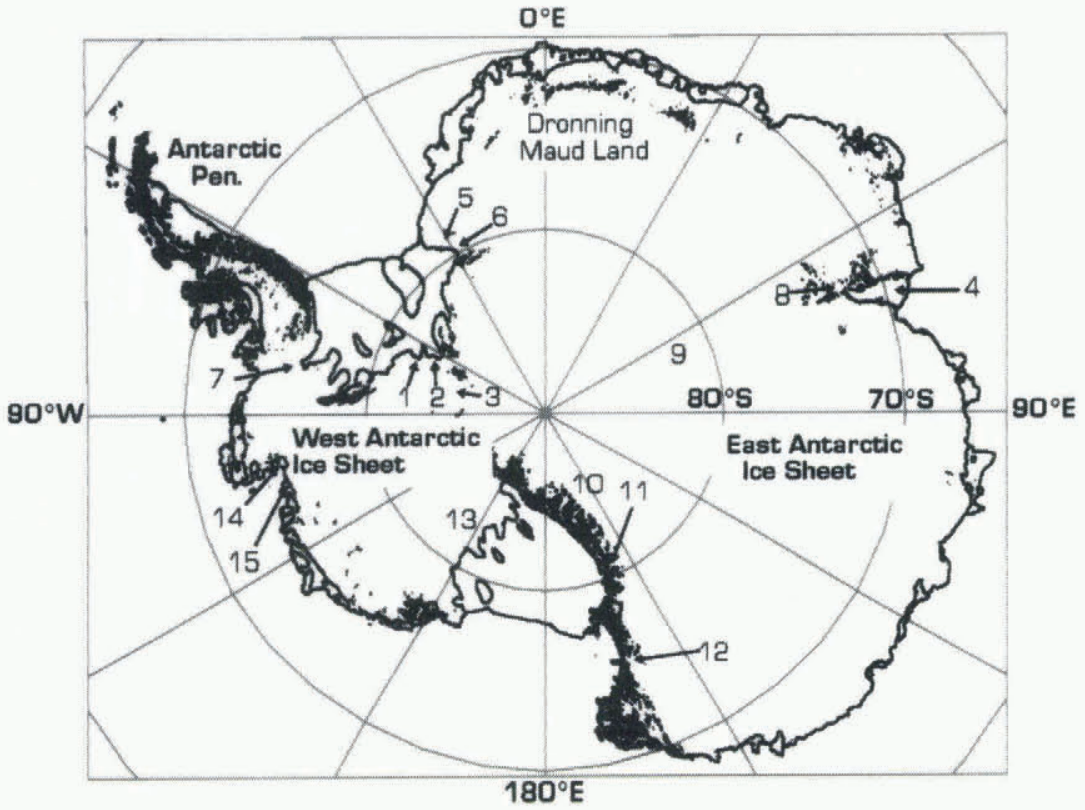

Fig. 1. Location map for Antarctica, with areas of rock outcrop filled. 1. Institute Ice Stream, 2. Foundation Ice Stream, 3. Patuxent Ice Stream, 4. Amery Ice Shelf, 5. Bailey Ice Stream, 6. Slessor Ice Stream, 7. Evans Ice Stream, 8. Lambert Glacier, 9. Dome Argus, 10. Transantartic Mountains, 11. Byrd Glacier, 12. David Glacier, 13. Siple Coast, 14. Pine Island Glacier, 15. Thwaites Glacier.
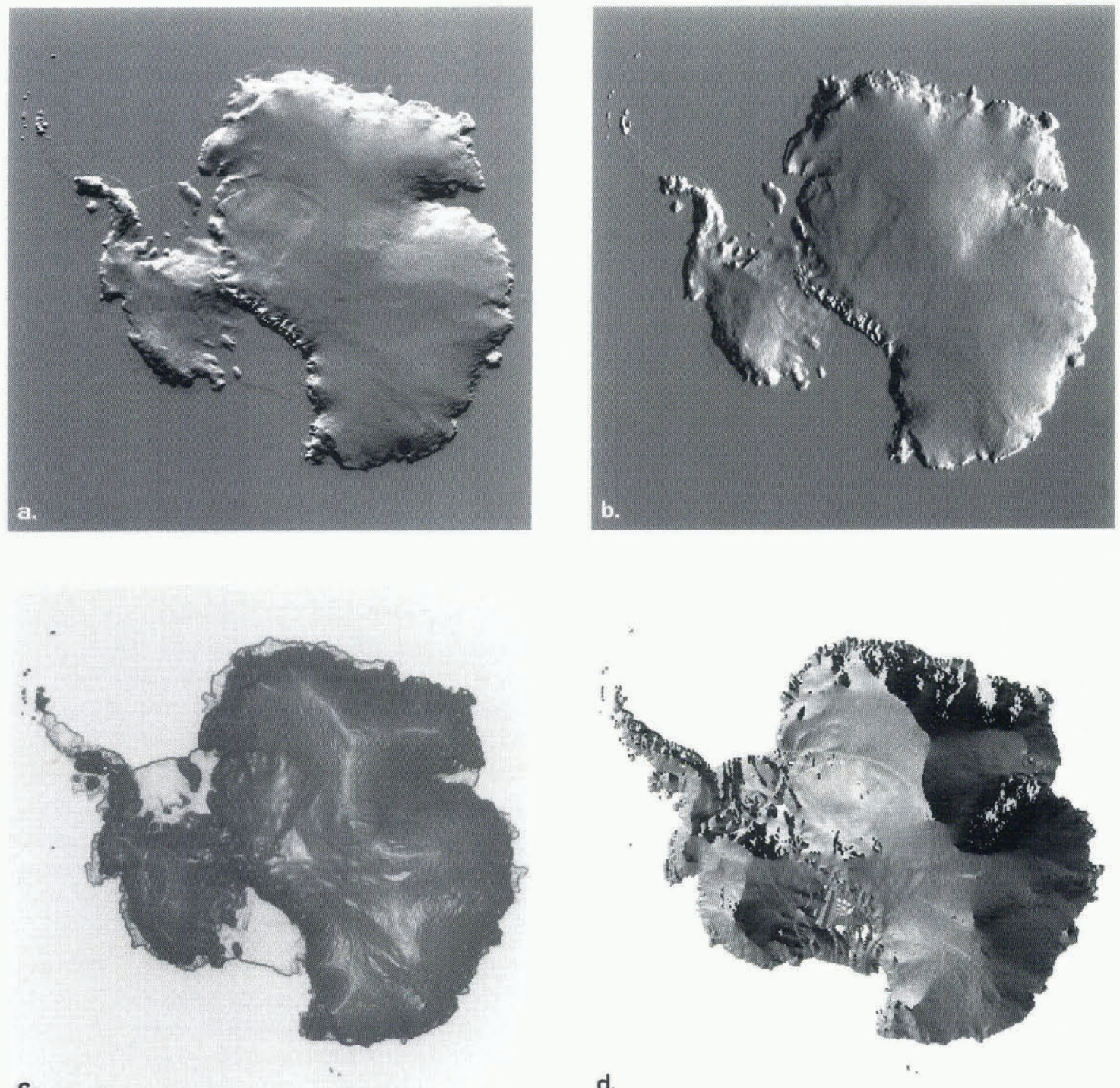

c.

d.

Fig. 2. Digital elevation model of Antarctica: the observed DEM. (a) Shaded surface relief with illumination from top of page. (b) Shaded surface relief with illumination from right side of page. (c) Shaded to show magnitude of surface slope, with steeper slopes shaded darker. (d) Shaded to show direction of surface slope. 
sounding flights have been used. In some areas the only data available were collected during the Tropical Wind Energy Conversion Reference Level Experiment (TWERLE) 1975-76 (Levanon and others, 1977; Levanon, 1982). While being an order of magnitude less accurate than satellite altimetry, these data are still valuable, having a worst-case error of around $\pm 60 \mathrm{~m}$ (Levanon and others, 1977).

All these data were gridded to $10 \mathrm{~km}$ resolution using methods described by Bamber and Huybrechts (1996). Throughout the paper we shall refer to this DEM as the observed DEM. Figure 2 presents the observed DEM as a series of images designed to highlight complementary aspects of the topography. The two shaded-relief maps (Fig. $2 \mathrm{a}$ and $\mathrm{b}$ ) give an impression of the overall shape of the ice sheet, while the map showing magnitude of surface slope (Fig. 2c) highlights flatter areas such as ridges, domes and lakes. Figure 2d shows the direction of maximum slope and serves to highlight the exact position of the ice divides and ridges.

\section{ICE-SHEET TOPOGRAPHY MODELS: MODELLED DEM}

The model of ice-sheet topography used in this study is the simple combination of two two-dimensional models. A plan-view model based on a continentality argument yields the shape of the predicted contours across the ice sheet. Elevations are then assigned to these contours using a theoretical two-dimensional ice-surface profile, to give a surfaceelevation contour map of the predicted ice sheet. Interpolating the contours onto the same grid as the observed DEM gives the modelled DEM.

\section{Continentality model}

Martin (1976) gave a practical demonstration of the way that the positions of ice divides are controlled by the shape of the margins of the ice sheet. As an analogue of ice he used sand, which he poured onto a platform with a complex shape reminiscent of the bed beneath an ice rise. As the addition of sand was gradual, a maximum load was eventually reached. In this state of self-ordered criticality the maximum supportable surface slope was achieved everywhere, except for those areas very close to the crests of the ridges. The positions of the crests/divides in this maximal system were easily observed under low-angle illumination and shown to occur midway between the edges of the platform. In this demonstration the sand behaves as a plastic material, which can support only a certain maximum critical stress before failure, making it a reasonable first-order analogue of ice (Paterson, 1994, ch. 5).

Reeh (1982) formalised and extended this analysis and showed analytically, assuming a plastic rheology and the absence of a strong bedrock slope, that an ice divide should occur equidistant from the margins. He went on to show that for the central Greenland ice sheet there are significant departures from the idealised divide positions. He concluded that this was due to a strong trend in bedrock elevation, the position of the ice divide being drawn towards bedrock ridges.

The experiment performed by Martin can now be simulated digitally. Given the shape of the margin of an ice sheet, it is an easy procedure to draw "contours of continentality": normals are constructed inland from the grounding
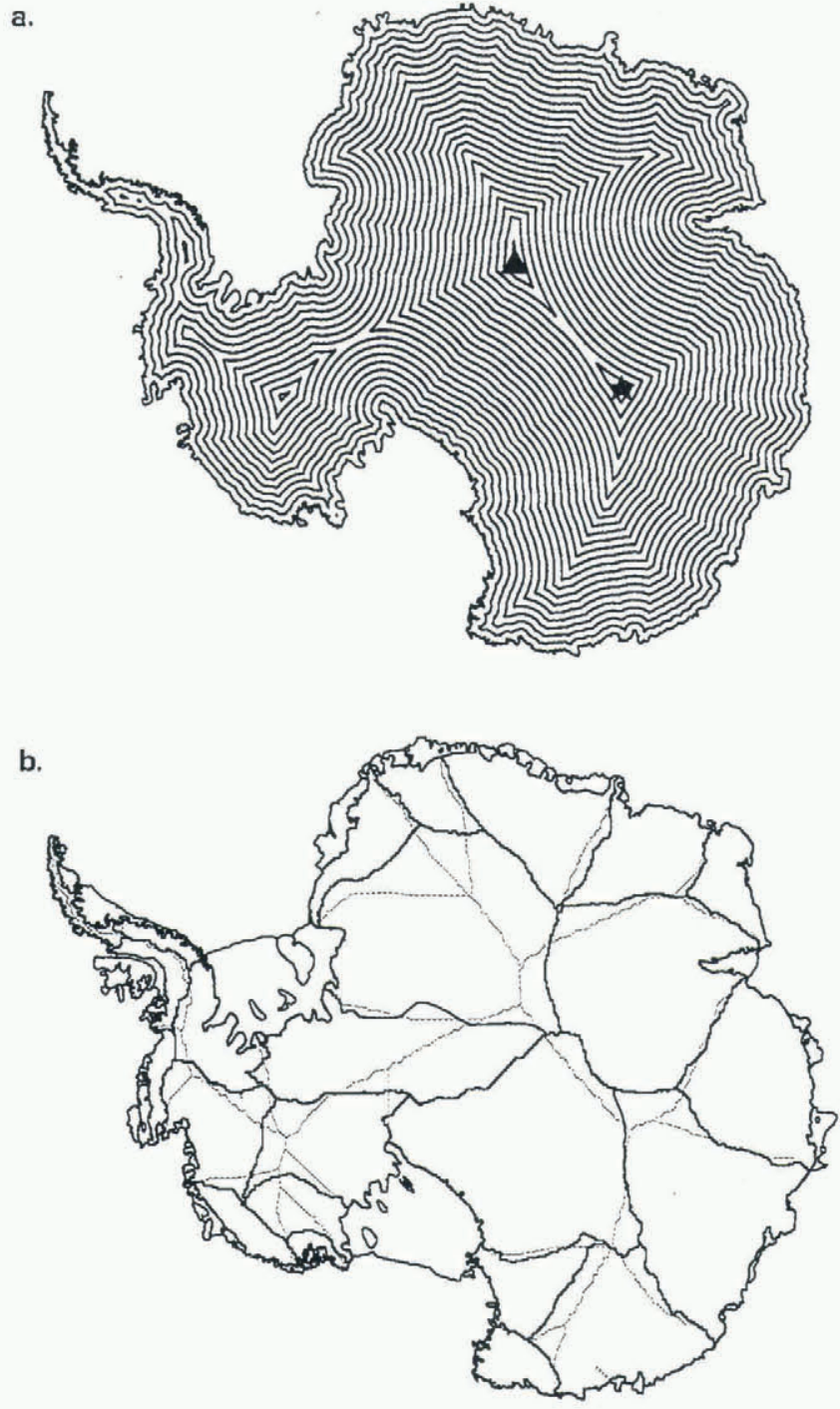

\begin{abstract}
Fig. 3. (a) Contours of continentality used as elevation contours to produce the modelled DEM. Generated from Antarctic Digital Database grounding line, buffered at $50 \mathrm{~km}$ intervals. The figure showes graphically that the Pole of Relative Inaccessibility for the contiguous continent is located at $82^{\circ} 50^{\prime} \mathrm{S}, 48^{\circ} 20^{\prime} \mathrm{E}$ (marked by triangle). This point is $1090 \mathrm{~km}$ away from that previously identified (marked by a star; BAS, 1993). (b) Ice-flow drainage basins derived from observed DEM (full lines) and from contours of continentality (grey lines).
\end{abstract}

line, and continentality is defined as the distance along that normal to the grounding line. This was done for Berkner Island, Antarctica, by Vaughan and others (1996) who showed that the pattern of the divides predicted in this way was indeed very similar to that seen in reality. For the present study the margin is taken to be the grounding line extracted from the Antarctic Digital Database (SCAR, 1993). In this case the contours of continentality were drawn (Fig. 3a) using the "buffering" algorithm available in the ARC/ Info Geographical Information System (GIS), but also in many similar products. Contours of continentality correspond to the elevation contours predicted by Reeh's plastic ice-sheet model, assuming a flat ice-sheet bed.

Figure $3 \mathrm{~b}$ shows a comparison of the drainage basins predicted by the continentality model with those derived from the observed DEM (cf. Fig. 2d). In many areas the correspondence between the positions of modelled and 
observed DEMs is good, with the largest areas of mismatch occurring in Dronning Maud Land and West Antarctica.

\section{Ice-sheet surface-elevation profile model}

A two-dimensional ice-sheet profile model (Vialov, 1958) was used to assign predicted surface elevations to the contours of continentality. Vialov (1958) showed that a model based on a power-law flow for ice yields a surface profile

$$
\left(\frac{h}{H}\right)^{2+2 / n}+\left(\frac{L-x}{L}\right)^{1+1 / n}=1
$$

where $h$ is the ice-sheet surface elevation, $H$ is surface elevation at the ice-sheet centre, $x$ is the distance from the icesheet margin, and $L$ is the distance from the ice-sheet centre to the margin. The flow-law parameter $n$ is taken to be 3 . We tune the overall surface elevation by matching the elevation at the Pole of Relative Inaccessibility (Fig. 3a) to the elevation of Dome Argus $(4050 \mathrm{~m})$. Having applied this elevation profile to the contours of continentality we interpolated the contour map onto a grid, to produce the modelled DEM.

One inconsistency in the approach is that the model assumes a zero ice-sheet thickness at the ice-sheet margin, which is assumed to be the grounding line. Since ice thickness at the grounding line is not generally zero, there will be a model/observed mismatch near the grounding line. However, the grounding-line ice thicknesses are almost everywhere less than $2000 \mathrm{~m}$, and around $1800 \mathrm{~m}$ of this is below sea level, so the mismatch due to this effect will only rarely exceed $200 \mathrm{~m}$. We will see later that this is not significant compared to other sources of mismatch.

Below we shall present results for power-law flow. We have also produced a modelled DEM using a theoretical two-dimensional surface profile derived for plastic flow (Nye, 1952), with very similar results. We therefore believe that our conclusions are largely insensitive to the choice of flow law.

\section{COMPARISON OF OBSERVED DEM AND MODELLED DEM}

Figure $4 \mathrm{a}$ and $\mathrm{b}$ shows the difference between observed DEM and modelled DEM. Only the areas of greatest mismatch (greater than $\pm 500 \mathrm{~m}$ ) are shaded, together with areas of mapped rock outcrop extracted from the Antarctic Digital Database (SCAR, 1993). The modelled DEM is on average only $300 \mathrm{~m}$ above the observed DEM. It is likely that accounting for variations in temperature and accumulation would have little effect on the model results, and we conclude that the gross areas of mismatch shown in Figure $4 \mathrm{a}$ and $\mathrm{b}$ are mainly the result of variations in bedrock conditions.

\section{Areas for which observed DEM is higher than mod- elled DEM}

Over much of the Antarctic ice sheet, the surface elevation does not closely reflect the topography of the bed that lies beneath it. In other words, the bed topography is generally buried so deep that it fails to redirect the ice flow at the surface. This can be seen by comparing the flowlines and bedrock topography given by Drewry (1983) and Drewry and Jordan (1983). This is, however, not the case where the bed protrudes through the ice-sheet surface, forming an outcrop or nunatak; here the ice flow is necessarily diverted around

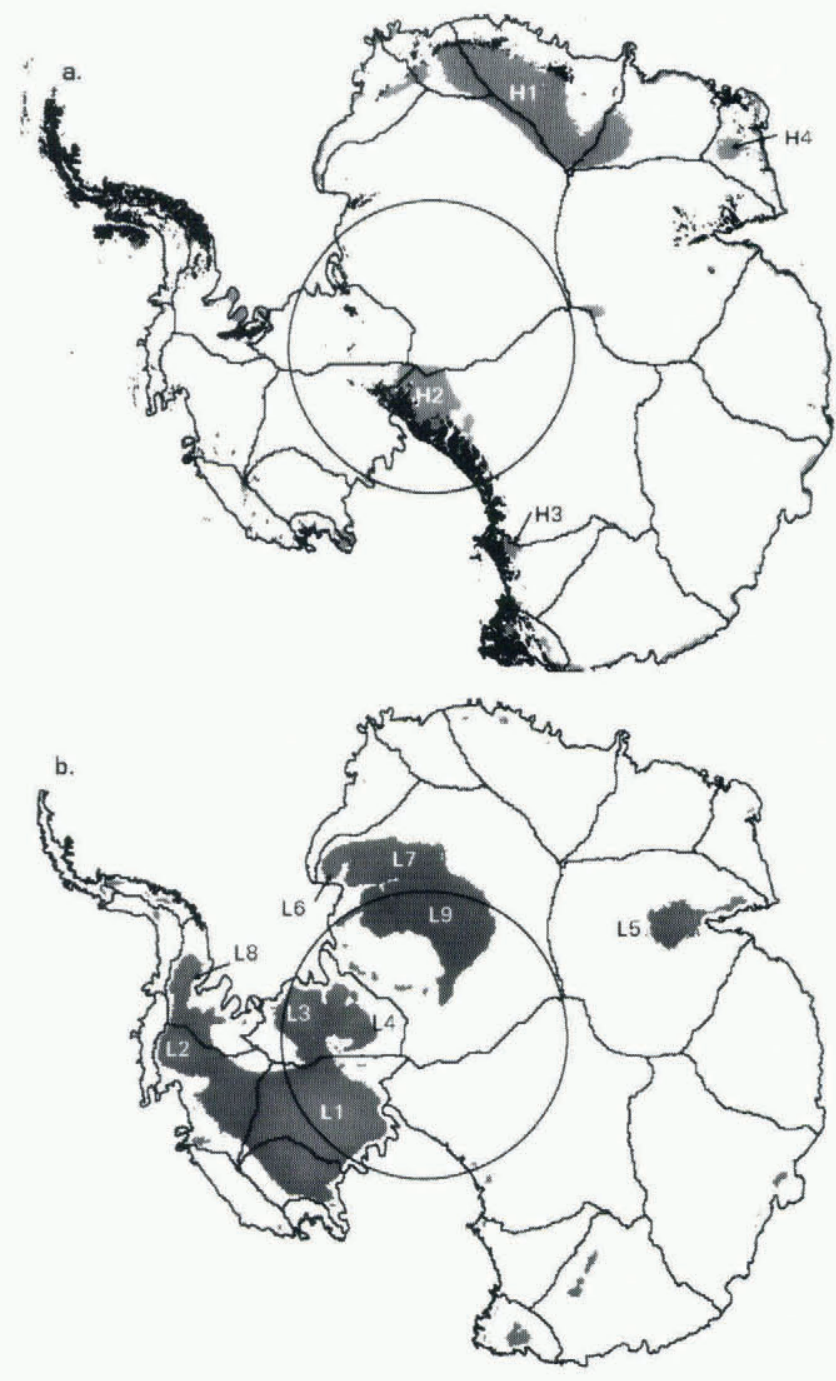

Fig. 4. Areas of difference between observed DEM and modelled DEM. (a) Areas where observed DEM is more than $500 \mathrm{~m}$ higher than modelled DEM (grey), with areas of rock outcrop (black) and extent of ERS-1 altimetry (circle) and drainage basins (full lines). (b) Areas where observed DEM is more than $500 \mathrm{~m}$ lower than modelled DEM (grey), and extent of ERS-1 altimetry (circle) and drainage basins (full lines). The labels identify areas discussed in the text.

the bed obstacle. Two effects cause outcrops to dam the ice flow and raise the ice-sheet surface upstream of outcrops. First, flow past the outcrop is genuinely obstructed and so the ice is at least partially dammed in the interior. To drive the ice through gaps between the outcrops requires a large local surface slope. Secondly, where ice flow is diverted around the outcrop, the actual distance which the ice must travel to reach the grounding line is increased. Here continentality underestimates the distance ice must flow to reach the grounding line. The ice surface is thus higher than would be predicted by the model used here, which causes an apparent damming. Together these two effects are largely responsible for the areas shown in Figure 4a, where the observed ice-sheet surface elevation is more than $500 \mathrm{~m}$ higher than the predicted surface elevations.

Areas $\mathrm{H} 1, \mathrm{H} 2, \mathrm{H} 3$ are directly upstream of extensive areas of rock outcrop associated with extensive mountain ranges. The distributions of these areas shows up several noteworthy points. The damming effect of moun- 
tain ranges in Dronning Maud Land $(\mathrm{Hl})$ appears to reach back into the drainage basin and beyond the ice divide into the neighbouring basins. The area of damming produced by the Transantarctic Mountains is not continuous, and the large glaciers that cut through the range (e.g. Byrd Glacier, David Glacier) appear to be powerful enough to lower ice-surface elevation on their hinterlands.

Area H4 and some smaller unlabelled areas on coastal promontories are not so easily interpreted as the result of damming by rock outcrops; rather, they are probably associated with elevated areas of bedrock.

\section{Areas for which observed DEM is lower than mod- elled DEM}

Where basal conditions of an ice sheet reduce the maximum sustainable basal shear stress, the ratio of ice velocity to surface slope is increased. This produces a low-profile ice sheet of the type described by Boulton and Jones (1979). Figure 4b shows the areas where the observed DEM is more than $500 \mathrm{~m}$ lower than the modelled DEM. Most of these are associated with reported areas of basal sliding.

Area Ll is an extensive area of low-profile ice sheet associated with Ice Streams A-E, Siple Coast (Shabtaie and others, 1987).

Area L2 is the drainage basin associated with Pine Island and Thwaites Glaciers, which Lindstrom and Hughes (1984) suggested suffers the "downdrawing" effect of Pine Island Glacier.

Area L3 is a low-profile portion of ice sheet occupying the area between Institute and Foundation Ice Streams. This area was noted by Jankowski and Drewry (1981) as giving unusual "ice-shelf-like" returns on airborne radar sounding records. They suggested that this area might be some "intermediate" between ice sheet and ice shelf, resting on soft, water-saturated sediments and presumably suffering a large degree of basal sliding.

Area L4 covers some of Foundation Ice Stream and its drainage basin, which is known to be flowing rapidly at more than $500 \mathrm{~m} \mathrm{a}^{-1}$ (Riedel and others, 1995), and Patuxent Ice Stream.

Area L5 covers Lambert Glacier and its hinterland. It should be noted that since the compilation of the Antarctic Digital Database the grounding line of Amery Ice Shelf has been reinterpreted (unpublished information from I. Allison and others) and the newly interpreted grounding line is considerably further inland. Thus, while it is likely that some of the surface anomaly in this area is real, it is also possible that the effect is the result of using an incorrect grounding line.

Areas L6 and L7 are associated with Bailey and Slessor Ice Streams, respectively. Both are highly active ice streams with considerable surface crevassing caused by the high stresses associated with strain rates. Area L8 is fed by the Evans Ice Stream and includes several tributary ice streams that converge and merge to form Evans Ice Stream (Jonas and Vaughan, 1996).

Area L9 is not previously identified as being associated with basal sliding or having a low-profile form.

\section{L9: A LOW-PROFILE ICE SHEET IN EAST ANTARCTICA?}

Almost all the areas of damming and areas of low-profile ice sheet identified in this exercise are easily explained in terms of known outcrops and known or suspected basal lubrication. Only area L9, an extensive region $\left(250000 \mathrm{~km}^{2}\right)$ of low-profile ice sheet within East Antarctica, remains unexplained. Such a large area of low-profile ice sheet has hitherto only been found in West Antarctica, where it is believed to be caused by massive ice-stream activity and basal lubrication. If L9 is the result of similar processes then it might cause us to rethink our ideas about the stability of the East Antarctic ice sheet.

It should be noted that much of area L9 lies beyond the limit of the ERS-1 altimeter data, and so the observed DEM in this region is less precise than elsewhere. Over this area it is derived largely from TWERLE balloon data, with a worst-case error of $\pm 60 \mathrm{~m}$ (Levanon and others, 1977). Thus, while the inaccuracy of the observed DEM in this area may contribute to the surface-elevation anomaly, it is unlikely that it can account for most of the difference between observed DEM and modelled DEM $(>500 \mathrm{~m})$. In the event that L9 is the result of defective TWERLE balloon data, then this in itself constitutes a substantial result when we remember how many other studies have directly or indirectly relied on these data.

Figure 3 shows that the positions of the modelled and observed ice divides exhibit greatest disagreement in the basin containing L9. This is, however, not a significant factor in disturbing the modelled elevations in L9, for two reasons. First, at any point on the ice sheet only the downstream distance to the grounding line is significant in determining the model elevation. Thus application of the observed ice-divide position in the model would cause no change in the modelled DEM in L9. Secondly, as surface slopes are low close to the ice divides of East Antarctica, divide position is sensitive to even modest differences in elevation.

We have found very few data of any type collected in this area which might confirm the interpretation of area L9. Only a few ice-thickness measurements are available, and so ice-bed elevation maps have been compiled from only a handful of points (e.g. Drewry and Jordan, 1983). Furthermore, no ice-velocity measurements appear to be available. There does, however, appear to be some corroborative evidence available from other modelling studies.

An area approximately corresponding to L9 was identified as having an unusually high sliding fraction by the model fitting of Fastook and Prentice (1994). A similar effect can be seen in the results of Huybrechts (1993, fig. 7) where it was interpreted as a region of anomalously high basal temperature. In neither of these studies was the area explained or discussed in any particular detail, or even noted as being contrary to current wisdom.

Budd and Warner (1996) used an ice-surface DEM derived from Drewry (1983) to calculate the ice flux required to balance observed surface accumulation data over the entire ice sheet. Their map of balance fluxes (Budd and Warner, 1996, fig. 1) does appear to show an area of high ice flux roughly coinciding with area L9. It is not, however, correct to simply interpret this high flux as high velocity, when the ice thickness is so poorly known. Furthermore, since Budd and Warner's DEM and the observed DEM were 
derived largely from the same data in this area, the two efforts cannot be seen as entirely independent results.

Clearly, area L9 deserves the attention of fieldworkers but would require a high logistical commitment. Perhaps the best hope for obtaining the required velocity data in the near future will come from the Canadian satellite Radarsat which carries a synthetic aperture radar (SAR). It has already been shown that fracture produced at icestream margins is visible in SAR imagery (Vaughan and others, 1994) and that ice-stream velocities can be derived from SAR images (Goldstein and others, 1993). Radarsat is scheduled to be reconfigured to acquire complete Antarctic coverage in September 1997.

\section{CONGLUSIONS}

This study has shown the value of even simple models when used in conjunction with good observational data, especially on a continental scale. In general, the results of the comparison are confirmation of our intuitive expectations based on known regional flow characteristics. Rock outcrops have a damming effect on the ice sheet which may dramatically shift the ice divide. Conversely, areas of basal sliding lower the ice-sheet surface and give rise to lowprofile ice sheets. The study has, however, been of further value, since it has identified an extensive region of lowprofile ice sheet reaching into the heart of the East Antarctic ice sheet (area L9), which needs to be checked by some other method at the earliest possible date.

\section{ACKNOWLEDGEMENTS}

We wish to thank colleagues, especially C.S. M. Doake, R. C.A. Hindmarsh and A. M. Smith for stimulating advice and A. P. R. Cooper for guidance in the use of the ARC/Info GIS. The comments of three reviewers led to major improvements in the manuscript.

\section{REFERENGES}

Bamber, J. L. 1994. A digital elevation model of the Antarctic ice sheet derived from ERS-1 altimeter data and comparison with terrestrial measurements. Ann. Glaciol., 20, 48-54.

Bamber, J. L. and P. Huybrechts. 1996. Geometric boundary conditions for modelling the velocity field of the Antarctic ice sheet. Ann. Glaciol., 23, 364-373.

Boulton, G. S. and A. S. Jones. 1979. Stability of temperate ice caps and ice sheets resting on beds of deformable sediment. F. Glaciol., 24(90), 29-43.

British Antarctic Survey (BAS). 1993. Antartica: a topographic database. Cambridge, British Antarctic Survey. (BAS (Misc.) 7, Scale 1:10 000000.$)$

Budd, W. F. and D. Jenssen. 1989. The dynamics of the Antarctic ice sheet. Ann. Glaciol., 12, 16-22.

Budd, W. F. and R. C. Warner. 1996. A computer scheme for rapid calculations of balance-flux distributions. Ann. Glaciol., 23, 21-27.

Drewry, D. J. 1983. The surface of the Antarctic ice sheet. In Drewry, D. J., ed. Antarctica: glaciological and geophysical folio. Cambridge, University of Cambridge. Scott Polar Research Institute, Sheet 2.

Drewry, D. J. and J. R. Jordan. 1983. The bedrock surface of Antarctica. In
Drewry, D. J., ed. Antarctica: glaciological and geophysical folio. Cambridge, University of Cambridge. Scott Polar Research Institute, Sheet 3.

Fabre, A., A. Letréguilly, C. Ritz and A. Mangeney. 1995. Greenland under changing climates: sensitivity experiments with a new three-dimensional ice-sheet model. Ann. Glaciol., 21, 1-7.

Fastook, J. L. and M. Prentice. 1994. A finite-element model of Antarctica: sensitivity test for meteorological mass-balance relationship. f. Glaciol., 40(134), 167-175.

Goldstein, R. M., H. Engelhardt, B. Kamb and R. M. Frolich. 1993. Satellite radar interferometry for monitoring ice sheet motion: application to an Antarctic ice stream. Science, 262(5139), 1525-1530.

Greve, R. and K. Hutter. 1995. Polythermal three-dimensional modelling of the Greenland ice sheet with varied geothermal heat flux. Ann. Glaciol., 21, 8-12.

Huybrechts, P. 1993. A numerical study on the response of the Antarctic ice sheet to changes in environmental conditions. In Caschetto, S., ed. Belgian Scientific Research Programme of the Antarctic. Scientific Results of Phase Two (10/1988-05/1992). Vol. 3. Brussels, Belgian Science Policy Office, 1-45.

Jankowski, E. J. and D. J. Drewry. 1981. The structure of West Antarctica from geophysical studies. Nature, 291 (5810), 17-21.

Jóhannesson, T., C. Raymond and E. D. Waddington. 1989. Time-scale for adjustment of glaciers to changes in mass balance. 7. Glaciol., 35(121), 355-369.

Jonas, M. and D. G. Vaughan. 1997. ERS-1 SAR mosaic of Filchner-Ronne Shelfeis. In Oerter, H., ed. Filchner-Ronne Ice Shelf Programme. Report 10. Bremerhaven, Alfred Wegener Institute for Polar and Marine Research, 47-49.

Levanon, N. 1982. Antarctic ice elevation maps from balloon altimetry. Ann. Glaciol., 3, 184-188.

Levanon, N., P. R. Julian and V. E. Suomi. 1977. Antarctic topography from balloons. Nature, 268(5620), 514-516.

Lindstrom, D. and T. J. Hughes. 1984. Downdraw of the Pine Island Bay drainage basins of the West Antarctic ice sheet. Antarct. J. U.S., 19(5), 56-58.

Martin, P. J. 1976. Ridges on Antarctic ice rises. F. Glaciol., 17(75), 141-144.

Nye, J. F. 1952. A comparison between the theoretical and the measured long profile of the Unteraar glacier. 7. Glaciol., 2(12), 103-107.

Paterson, W. S. B. 1994. The physics of glaciers. Third edition. Oxford, etc., Elsevier.

Reeh, N. 1982. A plasticity theory approach to the steady-state shape of a three-dimensional ice sheet. f. Glaciol., 28(100), 431-455.

Riedel, B., A. Karsten, B. Ritter and W. Niemeier. 1995. Geodetic work along Foundation Ice Stream. In Oerter, H., ed. Filchner-Ronne Ice Shelf Programme. Report 9. Bremerhaven, Alfred Wegener Institute for Polar and Marine Research, 101-106.

Scientific Committee on Antarctic Research (SCAR). 1993. Antarctic digital database. A topographic database for use with PC ARC/INFO, ArcView ${ }^{T M}$ and ArcCAD ${ }^{T M}$. CD-ROM version 1.0, September 1993 edition. Cambridge, Scott Polar Research Institute, British Antarctic Survey and the World Conservation Monitoring Centre.

Shabtaie, S., I. M. Whillans and C. R. Bentley. 1987. The morphology of Ice Streams A, B, and C, West Antarctica, and their environs. 7. Geophys. Res., 92(B9), 8865-8883.

Vaughan, D. G., R. M. Frolich and C. S. M. Doake. 1994. ERS-1 SAR: stress indicator for Antarctic ice streams. In Space at the Service of our Environment. Proceedings of the Second ERS-1 Symposium, 11-14 October 1993, Hamburg, Germany. Vol. 1. Paris, European Space Agency, 183-186. (ESA SP-361.)

Vaughan, D. G. and 9 others. 1996. Thematic maps of Filchner-Ronne-Shelfeis, Antarctica: subglacial and seabed topography, ice thickness and water column thickness. Polarforschung, 64(2), 1994, 75-88.

Vialov, S. S. 1958. Regularities of glacial shields movement and the theory of plastic viscours [sic] flow. International Association of Scientific Hydrology Publication 47 (Symposium at Chamonix 1958 - Physics of the Movement of the Ice), 266-275.

Waddington, E. D. and G. K. C. Clarke. 1988. Stable-isotope pattern predicted in surge-type glaciers. Can. 7. Earth Sci., 25(5), 657-668.

Whillans, I. M. and S. J. Johnsen. 1983. Longitudinal variations in glacial flow: theory and test using data from the Byrd Station strain network, Antarctica. 7. Glaciol., 29(101), 78-97. 